\title{
Experimental Design Approach for Optimization of Sucrose Fluid Bed Drying Process Conditions
}

\author{
Amira Touil ${ }^{1}$ and Ahlem Haj Ammar ${ }^{1}$ \\ ${ }^{1}$ High Institute of Environment Science and Technology, Technopole Borj Cedria, Tunisia
}

Submission: September 23, 2017; Published: November 20, 2017

*Corresponding author: Amira Touil, High Institute of Environment Science and Technology, Technopole Borj Cedria, 1003 Hammam-Lif, Tunisia, Tell: 0021698271183; Email: amira.touil@gmail.com

Abstract

The present study investigated the effect of operating parameters of sucrose fluid bed drying on powder quality and on drying time, in order to optimize the production of sucrose powders. A 24-1 fractional factorial design of experiment has been used. After an appropriate choice of four critical variables. 8 experiments led to a mathematical model as a first degree polynomial presenting the response functions (color and drying time) in relation to the operating parameters. From the retained model, we were able to calculate the average response, the different effects and their interactions. The results showed that gas flow and sugar particle size had significant effects (in absolute values) on the quality of the sugar dried, at a 95\% confidence interval. Sucrose presented the best quality and the lower time treatment at the lower gas flow rate and at larger particle size. Analyzing the variance (ANOVA) showed that the model is highly significant and can adequately describe the experimental range.

Keywords: Fractional factorial design; Sucrose; Quality; Fluid bed drying; Optimization

\section{Introduction}

Sugar is the organic compound commonly known as sucrose. A white, odorless, crystalline powder with a sweet taste, it is best known for its nutritional role. Sucrose can be found in many medical dosage forms such as chewable tablets, syrups, lozenges, or gums. Sugar-free formulations of many of these dosage forms exist as well. While sugar is essentially non-toxic it can be associated with dental caries, exacerbation of diabetes, and weight gain. The molecule is a disaccharide composed of the monosaccharides glucose and fructose with the molecular formula $\mathrm{C}_{12} \mathrm{H}_{22} \mathrm{O}_{11}$.

The sugar crystal is composed in units of two molecules. Which crystallize in the monoclinic system forming hemimorphic crystals [1]. "Monoclinic" refers to a crystal with six faces and three axes of unequal length. Two axes are at right angles to each other and the third is inclined to the plane of the other two. The structure is an open one and permits the inclusion of other molecules, such as H2O, within the crystal shape. In practical manufacturing terms the sugar molecules will often attach themselves to other solid particles and molecules as a base for development of the crystal and, thus, the sugar crystal will almost always include foreign matter within the crystal. This will normally have no impact on white sugar quality as the particulates are very small, but detailed analysis of a solution derived from the crystals will reveal other elements. Because of the open molecular structure, detailed above, of the sugar crystal, moisture, or $\mathrm{H}_{2} \mathrm{O}$ molecules will be present in the crystal structure and can be divided into three types [2] of which only two can be analytically measured:

A. Surface water content; the water adhering to the surfaces of the sugar crystal and removed by evaporative drying. This can be measured using the Karl Fischer method with water-free ethanol as a dispersing agent.

B. Included water content; not able to be measured because it is not possible to extract it from the crystal structure.

C. Total water content; by measuring this value, using the Karl Fischer method with a solvent, such as Formamide, as a solvent for the sugar, the inclusion sugar content can be determined by subtraction.

In freshly dried sugar, the Total water content should be $<0.1 \%$ with the Surface water content being $0.03-0.05 \%$, leaving $0.07-0.05 \%$ of Inclusion water content. The problem with the inclusion water content is that it is very difficult to extract, but will migrate slowly to the outer surface of the crystal over time in storage. The quantity of water involved in Inclusion 
water is a significant percentage of the Total water content of dried sugar and "caking". lumping together of sugar crystals can occur readily in storage, depending on the temperature relative to ambient and relative humidity in the storage facility. To produce granulated sugar in which the individual sugar grains do not clump together, sugar must be dried. Drying is accomplished first by drying the sugar in a hot dryer, and then by blowing cool air through it for several days in so-called conditioning silos. The finished product is stored in large concrete or steel silos. Thus, the drying process is a critical step in the sugar industries which can affect directly the quality of the final product.

Sugar drying systems have been developed by a number of different companies and utilizing different approaches to drying in terms of temperature, air flow direction and volumes, retention time, all based on an assumed crystal quality. The equipment developed and commonly used includes: Rotary Drum Dryer, with an air flow co-current with the sugar flow; Rotary Drum Dryer and Cooler, with air flow counter-current with the sugar flow; Rotary Drum Dryer/Cooler. With air flow co-and counter-current with sugar flow; and. Fluidized Bed Dryer and Cooler, where air is cross-flow, at 90 degrees to sugar flow. Other equipment including belt-type dryer, tray dryer and column cooler is occasionally used.

The theory of sugar drying is not affected by the equipment, but the air flow characteristics may be better in counter-current than in co-current units. In fact, industrial drying operations require a high rate of heat and mass transfer and a high rate of solid transport to or from the dryer. Therefore, Fluidized Bed technology is very used in sugar industries. Since, this technology in drying application is characterized with large contact surface area between solids and gas, high thermal inertia of solids, good degree of solids mixing, and rapid transfer of heat and moisture between solids and gas that shortens drying time considerably without damaging heat sensitive materials.

Fluidization is a technique in which a bed of solid particles is transformed to a liquid-like condition by passing a stream of fluid through the solid bed. At a sufficiently high velocity that frictional forces between the particles and flowing fluid counterbalance the weight of particles. Above this velocity, the pressure drop across the bed is always constant even though fluid velocity increases. This velocity is referred to as the minimum fluidization velocity. Fluidized bed technology has been used in industrial dryers for the drying of wet solid particles for many years. Fluidized bed dryers have successfully been used for drying of products such as coal, maize, paddy, coconut, biosynthesis products, chillies, nylon, baker's yeast, black tea, bleaching agents (sodium perborate) and sugar [3-14].

Keeping the advantages Fluidized bed drying, e.g., high rates of drying due to an excellent contact between the drying medium and the drying product, high thermal efficiency. And relatively low cost of operation [15], along with the hope of obtaining a higher-quality product, a fluidized bed dryer was proposed as an alternative for drying sugar in the present study. Although numerous works have been reported on the use of a fluidized bed dryer to dry various food and agricultural products [1619], no data is available on its use to optimize the sugar quality. Therefore, batch fluidized bed drying experiments of sugar were performed and the effects of various drying conditions on the drying kinetics and some quality attributes of the dried product were investigated. An attempt was also made to identify a suitable drying condition that would yield a product that is comparable in quality, in terms of moisture content, color and time drying, to the reference product that is acceptable to the consumer.

\section{Material and Methods}

\section{Material}

The wet sugar used in this drying experiment obtained directly from the sugar plant in Beja Tunisia after centrifugation at different particle size.

\section{Experimental set-up}

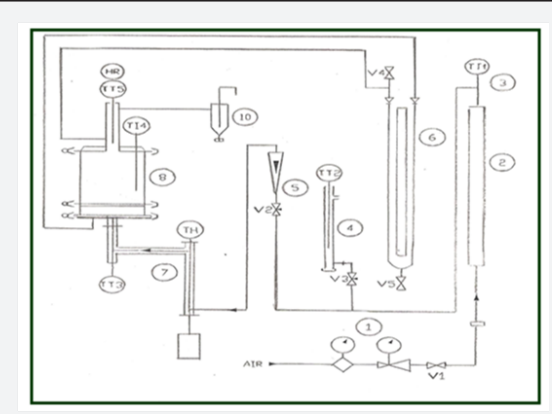

Figure 1: Layout of batch fluidized bed drying process.

1: compressed air supply. 2: silica gel column. 3: air dry thermometer. 4: wet thermometer. 5 flowmeter. 6 piezometric tube. 7 electrical resistance. 8 fluidized bed 9 transmeteur relative humidity and temperature. 10 hurricane glass. V1: isolation valve $\mathrm{V} 2$ control valve airflow entering the fluidized bed. V3: control valve air flow derived for feature measure the air wet bulb V4 valve venting piezometric tube V5 drain valve piezometric tube.

Equipment: Fluidized bed dryer model FGS/2000, PIGNAT. French as shown in Figure 1, used for the experiment. This fluidized bed is cylindrical, approximately $18 \mathrm{~cm}$ in diameter and $32 \mathrm{~cm}$ high, with a voltage of $230 \mathrm{~V} 50 \mathrm{~Hz}$.

Drying experiments: The wet sugar used in this drying experiment obtained directly from the sugar plant in Beja Tunisia. Initial moisture content of the samples was determined by drying it in an oven model VENTICELL from MMM Med center $\mathrm{GmbH}$. Germany at $105^{\circ} \mathrm{C}$ for 1 day. As the fluidized bed is switched on the hot air flow will circulate for about $10 \mathrm{~min}$ until an established condition is achieved in the bed before the experiment begins. This step aims to reduce the heat loss through the bed's wall that is still cold in the initial stage of the experiment. $0.5 \mathrm{~kg}$ of the sugar samples were put into the 
fluidized bed and the experiment begins. Parameters studied in this experiment were moisture content drying rates, drying time, air velocity and temperature. Parameters have been determined as shown in Table 1. Moisture content on sugar calculated on a dry base $(\mathrm{db})$ basis using the following equation:

Table 1: Factors and levels used in the experiment.

\begin{tabular}{|c|c|c|c|}
\hline \multirow{3}{*}{ Level } & & -1 & 1 \\
\hline \multirow{3}{*}{ Factors } & $\mathrm{X}_{1}$ Temperature $\left({ }^{\circ} \mathrm{C}\right)$ & 40 & 60 \\
\cline { 2 - 4 } & $\mathrm{X}_{2}$ Pressure $(\mathrm{bar})$ & 2.5 & 3 \\
\cline { 2 - 4 } & $\mathrm{X}_{3}$ Gas flow $\left(\mathrm{Nm}^{3} / \mathrm{h}\right)$ & 3.5 & 4 \\
\cline { 2 - 4 } & $\mathrm{X}_{4}$ Sugar particle size $(\mu \mathrm{m})$ & 100 & 500 \\
\hline \multirow{2}{*}{ Responses } & \multicolumn{2}{|c|}{$\mathrm{Y}_{1}$ Color $(\mathrm{IU})$} \\
\hline & $\mathrm{Y}_{2}$ Drying time (min) \\
\hline
\end{tabular}

$$
x(d b)=\frac{w_{t}-w_{k}}{w_{k}} \times 100
$$

Where $x(a b)$ is a fraction of moisture content; $\mathrm{W}_{\mathrm{t}}$ is the sample weight at a specific time; $\mathrm{W}_{\mathrm{k}}$ is the sample dry weight (g).

\section{Coloration}

According (ICUMSA 1994) the measurement is made by UVSpectrophotometry at $420 \mathrm{~nm}$ for a sweet solution (50g of sugar / 100g water).

ICUMSA unit is used (abbreviated IU $=1000^{*} \mathrm{E} 420 /\left(\mathrm{l}^{*} \mathrm{w}^{*} \mathrm{~d}\right)$ with $\mathrm{l}$ is the length of the tank, E420 absorbance of the solution, $w$ the title in grams per 100 grams and $d$ the apparent density. The solution is previously filtered to avoid interference of suspended solids. In the European Union, the point of color is often used defined as: 1 point=7.5IU.

\section{Experimental design}

Statistical experimental design methods provide a systematic and efficient plan for experimental work in order to achieve the goal in controlling many factors simultaneously. Referred to Taguchi design method, four factors at each level were adopted. The fractional factorial design $\left(2^{4-1}\right)$ used was a standard L8 orthogonal array. This orthogonal array was chosen because of its minimum number of experiments trials. Each row of the matrix represented a trial. However, the sequence in which those trials were carried out was taken as random. A '-1' or a ' 1 ' represented the two levels of each factor in the matrix. For such a matrix, 12 experiments were required: 8 for the fractional factorial matrix $\left(2^{4-1}\right)$ and four carried out at the centre. The duplication of centre points, coded 0 , is used to determine the experimental error. In our case, four central replicates were employed. The experiments were run in random order to avoid systematic errors due to extraneous factors. The factors and levels for the experimental design were given in Table 1.

Temperature and pressure levels were chosen by considering the operating limits of the experimental apparatus and taking account the deterioration of the product. The choice of the gas flow levels was confirmed by the fluidization experiment which consists of varying gas flow and measuring the pressure loss of the fluidized bed (Figure 2). Finally, sugar particle size was chosen according to the particle size of commercially available sugar.

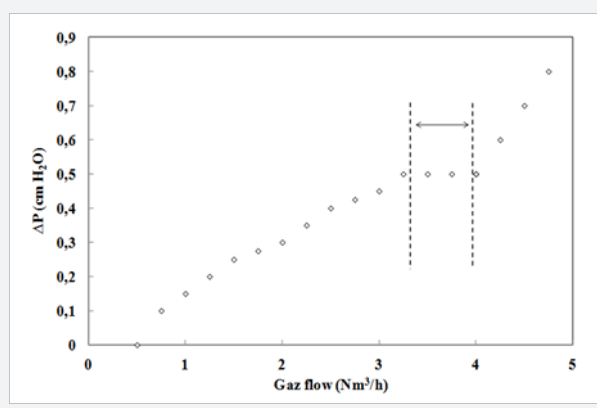

Figure 2: Fluidization experiment.

For gas flow values lower than $3 \mathrm{Nm} 3 / \mathrm{h}$, the particles bed remains stationary and the pressure loss increases with rate of gas injection. From the flow of $3 \mathrm{Nm} 3 / \mathrm{h}$, there is an expansion of the particles bed without increasing the pressure drop. In other words the fluid velocity at $3 \mathrm{Nm} 3 / \mathrm{h}$ corresponds to the minimum fluidization velocity. From 3 to $4 \mathrm{Nm} 3 / \mathrm{h}$ along the path, the pressure drop remains constant as a function of speed. From 3 to $4 \mathrm{Nm} 3 / \mathrm{h}$, the particles are entrained in the flow direction of the fluid.

\section{Mathematical model}

Table 2: Factorial effects (Contrasts).

\begin{tabular}{|c|c|c|c|c|c|c|c|}
\hline MOY & $\mathbf{X}_{\mathbf{1}}$ & $\mathbf{X}_{\mathbf{2}}$ & $\mathbf{X}_{\mathbf{3}}$ & $\mathbf{X}_{\mathbf{1}} \mathbf{X}_{\mathbf{2}}$ & $\mathbf{X}_{\mathbf{1}} \mathbf{X}_{\mathbf{3}}$ & $\mathbf{X}_{\mathbf{2}} \mathbf{X}_{\mathbf{3}}$ & $\mathbf{X}_{\mathbf{1}} \mathbf{X}_{\mathbf{2}} \mathbf{X}_{\mathbf{3}}=\mathbf{X}_{\mathbf{4}}$ \\
\hline 1 & -1 & -1 & -1 & 1 & 1 & 1 & -1 \\
\hline 1 & 1 & -1 & -1 & -1 & -1 & 1 \\
\hline 1 & -1 & 1 & -1 & -1 & 1 & -1 & -1 \\
\hline 1 & 1 & 1 & -1 & 1 & -1 & -1 & -1 \\
\hline 1 & -1 & -1 & 1 & 1 & -1 & -1 & -1 \\
\hline 1 & 1 & -1 & 1 & -1 & -1 & 1 & -1 \\
\hline 1 & -1 & 1 & 1 & -1 & 1 & & 1 \\
\hline
\end{tabular}


To construct a fractional design $2^{4-1}$, we have select 3 factors $\left(\mathrm{X}_{1}, \mathrm{X}_{2}\right.$ and $\left.\mathrm{X}_{3}\right)$ to form a 23 full factorial (basic design) then we have confound (alias) $X_{4}$ with a high order interaction of $\mathrm{X}_{1}, \mathrm{X}_{2}$ and $\mathrm{X}_{3}$. i.e. $\mathrm{X}_{1} \mathrm{X}_{2} \mathrm{X}_{3}=\mathrm{X}_{4}$ (Table 2). In such fractional factorial design, a linear mathematical model of the measured response $(\mathrm{Y})$ is often applied for the evaluation of the influence of the investigated factors (Xi). This first-degree polynomial is described by equation (2):

$$
Y=h_{0}+h_{1} X_{1}+h_{2} X_{2}+h_{3} X_{3}+h_{4} X_{1} X_{2}+h_{5} X_{1} X_{3}+h_{6} X_{2} X_{3}+h_{7} X_{1} X_{2} X_{3}+\varepsilon
$$

Where $h_{0}$ represents the average theoretical value of the response. Coefficients $h_{1}, h_{2}$ and $h_{3}$ represent the factor effects of $\mathrm{X}_{1}, \mathrm{X}_{2}$ and $\mathrm{X}_{3}$, respectively. The coefficients $\mathrm{h} 4, \mathrm{~h} 5, \mathrm{~h} 6$ and $\mathrm{h} 7$, represent the interaction effects of $\mathrm{X}_{1} \mathrm{X}_{2}, \mathrm{X}_{1} \mathrm{X}_{3}, \mathrm{X}_{2} \mathrm{X}_{3}$ and $\mathrm{X}_{1} \mathrm{X}_{2} \mathrm{X}_{3}$. Respectively, and $\varepsilon$ is an error term.

\section{Statistical analysis}

The analysis of results was performed with statistical and graphical analysis software STATGRAPHICS Centurion 17.1.08. This software was used for regression analysis of the obtained data. ANOVA (analysis of variance), which is the statistical testing of the model in the form of a linear term and an interaction term, was also used to test the significance of each term in equation 2 and the fitness of the obtained regression model.

\section{Results and Discussion}

\section{Drying curves}

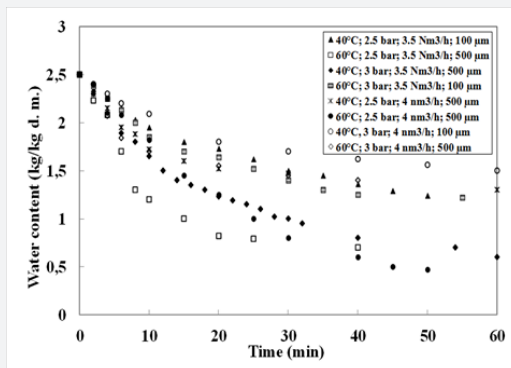

Figure 3: Moisture content curve in dry base. versus drying time at different operational conditions.

Figure 3 shows the profile of moisture content changes at various drying times in different operational conditions.

This Figure shows the effect of air flow, pressure, particle size and operation temperature upon the sugar drying kinetic curve. The overall finding show that at a fixed pressure, particle size and operation temperature, the use of high air flow can shorten the drying time. At a temperature of $60^{\circ} \mathrm{C}$ and pressure of 3 bar, air flow of $3.5 \mathrm{Nm} 3 / \mathrm{h}$ and $4 \mathrm{Nm} 3 / \mathrm{h}$ produced an almost identical curve. On the other hand, $3.5 \mathrm{Nm} 3 / \mathrm{h}$ air flow, at a temperature of $60{ }^{\circ} \mathrm{C}$ and pressure of $2.5 \mathrm{bar}$, caused a slower reduction of moisture content.

This could be because at high temperatures, the transfer of mass and heat is high and water vapor loss is excessive even at low air velocity. At low operation temperatures, the rate of heat transfer is low and air velocity plays a vital role in causing more water vapor to dissipate during airflows. Ertekin and Yaldiz reported the same phenomenon in eggplant drying.

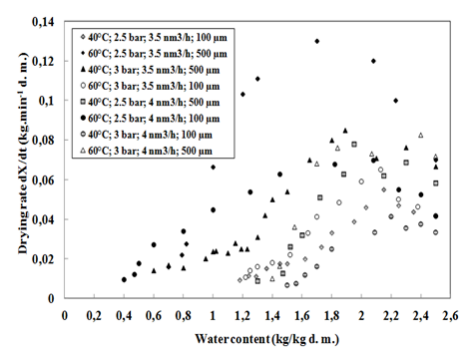

Figure 4: Drying rate curve, $d X / d t$ in dry base, against water content at different operational conditions.

For an air flow of $3.52 \mathrm{Nm} 3 / \mathrm{h}$ the difference of drying kinetics curve is more apparent at different pressures shown in Figure 4 while moisture content reduced at a slower rate on low pressure. At a fixed airflow, pressure and particle size moisture content reduces rapidly with an increase in temperature (Figure 3). In addition, at fixed temperature, airflow and pressure it was found that the reduction of moisture content at a particle size of $100 \mu \mathrm{m}$ was slow and widespread in comparison with $500 \mu \mathrm{m}$. Figure 4 shows the changes in drying rate in dry base with water content at different operational situations.

In general, it observed that drying rate reduces with the reduction of moisture content. The drying of sugar seems to follow the classic theory of the drying process but the mechanisms involved are quite different. These curves show a short initial eternal stage and a pseudo-constant rate stage in which the film of syrup on the surface of the crystals is under saturated and water evaporates freely at a nearly constant rate. In the falling rate stage, the surface film has become sufficiently concentrated-evaporation is slowed significantly. Crystallization of sucrose begins from the supersaturated film. The higher the purity of sugar, the faster the crystallization rate. During the important falling rate stage, two physical processes take place simultaneously: Water evaporation from the syrup layer and Sugar contained in the syrup layer crystallizes.

The growth of the microcrystalline layer on top of the syrup layer determines the diffusion rate of the water through this layer to the outside. A certain maximum crystallization rate cannot be exceeded. If the rate at which the crystals dry is higher than the rate at which the sugar contained in the solution can crystallize, amorphous sugar will form, which can reduce the diffusion of water significantly. The result is sugar with high residual moisture content.

\section{The factorial experimental design results}

The observed response values with different combinations of the four variables used in our experimental design are listed in Table 3. 
Table 3: Design matrix of 24-1 fractional design.

\begin{tabular}{|c|c|c|c|c|c|c|c|c|c|c|c|}
\hline & Experiment & MOY & $\mathrm{X}_{1}$ & $\mathbf{X}_{2}$ & $\mathrm{X}_{3}$ & $\mathrm{X}_{1} \mathrm{X}_{2}$ & $\mathrm{X}_{1} \mathrm{X}_{3}$ & $\mathrm{X}_{2} \mathrm{X}_{3}$ & $X_{1} X_{2} X_{3}=X_{4}$ & $Y_{1}$ & $Y_{2}$ \\
\hline \multirow{9}{*}{$\begin{array}{c}2^{4-1} \\
\text { Fractional } \\
\text { design }\end{array}$} & E1 & 1 & -1 & -1 & -1 & 1 & 1 & 1 & -1 & 100 & 30 \\
\hline & E2 & 1 & 1 & -1 & -1 & -1 & -1 & 1 & 1 & 49.177 & 5.5 \\
\hline & E3 & 1 & -1 & 1 & -1 & -1 & 1 & -1 & 1 & 22.25 & 12 \\
\hline & $\mathrm{E} 4$ & 1 & 1 & 1 & -1 & 1 & -1 & -1 & -1 & 111.89 & 25 \\
\hline & E5 & 1 & -1 & -1 & 1 & 1 & -1 & -1 & 1 & 9.445 & 49 \\
\hline & E6 & 1 & 1 & -1 & 1 & -1 & 1 & -1 & -1 & 65.553 & 14 \\
\hline & E7 & 1 & -1 & 1 & 1 & -1 & -1 & 1 & -1 & 27.722 & 60 \\
\hline & E8 & 1 & 1 & 1 & 1 & 1 & 1 & 1 & 1 & 50.365 & 27 \\
\hline & Contrast & $\mathrm{h}_{0}$ & $\mathrm{~h}_{1}$ & $\mathrm{~h}_{2}$ & $\mathrm{~h}_{3}$ & $\mathrm{~h}_{4}$ & $\mathrm{~h}_{5}$ & $\mathrm{~h}_{6}$ & $\mathrm{~h}_{7}$ & & \\
\hline \multirow[t]{4}{*}{ Centre points } & E9 & 0 & 0 & 0 & 0 & 0 & 0 & 0 & 0 & 53.81 & 27.54 \\
\hline & E10 & 0 & 0 & 0 & 0 & 0 & 0 & 0 & 0 & 54.23 & 27.02 \\
\hline & E11 & 0 & 0 & 0 & 0 & 0 & 0 & 0 & 0 & 55.07 & 28.36 \\
\hline & E12 & 0 & 0 & 0 & 0 & 0 & 0 & 0 & 0 & 52.69 & 27.89 \\
\hline
\end{tabular}

Effect studies of factors and their interactions: To optimize fluid bed drying conditions of sugar, a fractional factorial design (FFD) optimization was conducted. The independent variables and response values shown in Table 3 were used to generate a mathematical model that expresses the behaviour of the experiment.

This model allows the assessment of predicted response $(\mathrm{Y})$ as a function of the independent variables and their interactions. The calculated models in terms of coded factors generated by FFD for the responses in this study is:

$$
Y_{1}=54.55+14.7 X_{1}-1.49 X_{2}-16.28 X_{3}-21.74 X_{4}+13.37 X_{1} X_{2}+4.99
$$
$\mathrm{X}_{1} \mathrm{X}_{3}+2.27 \mathrm{X}_{2} \mathrm{X}_{3}+0.99$

$$
Y_{2}=27.81-9.94 X_{1}+3.19 X_{2}+9.69 X_{3}-4.44 X_{4}+4.94 X_{1} X_{2}-7.06
$$
$\mathrm{X}_{1} \mathrm{X}_{3}+2.81 \mathrm{X}_{2} \mathrm{X}_{3}+0.57$

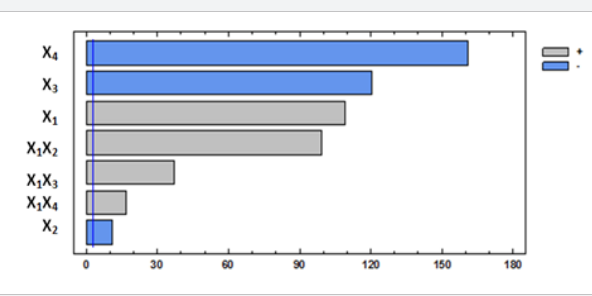

Figure 5: Pareto chart representation of the parameter effects on the "color".

The values of the constant were found to be 54.55 for color and 27.81 for drying time. A positive sign of the coefficient represents a synergistic effect, while a negative sign indicates an antagonist effect. Figure 5 and Figure 6 show the corresponding Pareto chart, used for identification of the most important factors. The length of the rod is proportional to the importance of the effect as can be seen, the effect of sugar particle size on color was the most important (in absolute value) (Figure 5) whereas the effect of gas flow and temperature were lower and nearly equal. Pressure is a factor of lesser importance. Drying time is mostly influenced by drying temperature and gas flow. However, these two factors have contradictory effects (Figure 6).

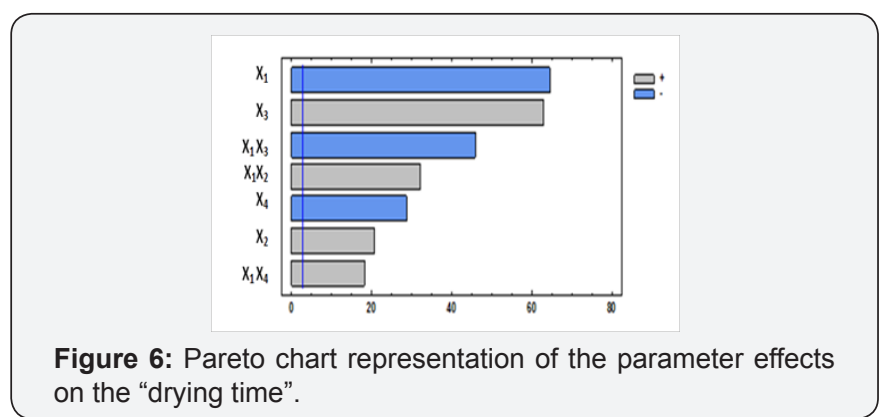

It should be interesting to determine the interactions between factors. An interaction is effective when the variation of the studied response from low to high levels of a factor is dependent on the second factor's level, only in the cases when the lines do not run parallel. From the interaction plots (Figure 5,6) it is shown that, for colour, the interaction $X_{1} X_{2}$ is more significant than interactions $\mathrm{X}_{1} \mathrm{X}_{3}$ and $\mathrm{X}_{1} \mathrm{X}_{4}$. However, for drying time interaction $\mathrm{X}_{1} \mathrm{X}_{3}$ is the most important. Table 3 shows the nonexistence of interactions $\mathrm{X}_{1} \mathrm{X}_{4}, \mathrm{X}_{2} \mathrm{X}_{4}$ and $\mathrm{X}_{3} \mathrm{X}_{4}$. These interactions would not be detected in univariate statistic techniques.

Fitted model: ANOVA tables (Tables 4,5) test the statistical significance of each effect by comparing the quadratic average to the estimate experimental error and check the quality of fitted model. The mean squares (MS) are obtained as follows:

$$
M S=S S / D F
$$

Where SS is the sum of squares due to the source and DF is the respective degrees of freedom. The F statistic equals the mean square for Model divided by the mean square for Error. $\mathrm{P}$ 


\section{Global Journal of Pharmacy \& Pharmaceutical Sciences}

is the probability of observing an $\mathrm{F}$ of Fobs or greater. The value here --0.1765, 0.8694, 0.1462 and 0.08-- (Table 4) and --0.1538,
$0.5855,0.1613$ and $0.4588--$ (Table 5 ) are greater than 0.05 , so we will not reject the null hypothesis $(\mathrm{P}$-value $\leq \alpha)$.

Table 4: ANOVA for the fitted model of "color".

\begin{tabular}{|c|c|c|c|c|c|}
\hline Source of variation & SS & DF & MS & $\mathbf{F}_{\text {obs }}$ & $P\left(F \geq F_{o b s}\right)$ \\
\hline $\mathrm{X}_{1}$ & 1727.78 & 1 & 1727.78 & 3.1 & 0.1765 \\
\hline $\mathrm{X}_{2}$ & 17.84 & 1 & 17.84 & 0.03 & 0.8694 \\
\hline $\mathrm{X}_{3}$ & 2120.05 & 1 & 2120.05 & 3.81 & 0.1462 \\
\hline $\mathrm{X}_{4}$ & 3781.37 & 1 & 3781.37 & 6.79 & 0.08 \\
\hline Error & 1671.48 & 3 & 557.16 & & \\
\hline Total & 9318.52 & 7 & & & \\
\hline $\mathrm{R}^{2}$ & 0.9999 & & & & \\
\hline $\mathrm{R}^{2}$ (adjusted for $\mathrm{df}$ ) & 0.999828 & & & & \\
\hline \multicolumn{6}{|c|}{ SS, sum of squares ; DF, degrees of freedom; MS, mean square } \\
\hline
\end{tabular}

Table 5: ANOVA for the fitted model of "drying time".

\begin{tabular}{|c|c|c|c|c|c|}
\hline Source of variation & SS & DF & MS & $F_{\text {obs }}$ & $P\left(F \geq F_{\text {obs }}\right)$ \\
\hline $\mathrm{X}_{1}$ & 790.03 & 1 & 790.03 & 3.61 & 0.1538 \\
\hline $\mathrm{X}_{2}$ & 81.28 & 1 & 81.28 & 0.037 & 0.5855 \\
\hline $\mathrm{X}_{3}$ & 750.78 & 1 & 750.78 & 3.43 & 0.1613 \\
\hline $\mathrm{X}_{4}$ & 157.53 & 1 & 157.53 & 0.72 & 0.4588 \\
\hline Error & 657.34 & 3 & 219.115 & & \\
\hline Total & 2436.97 & 7 & & & \\
\hline $\mathrm{R}^{2}$ & 0.9996 & & & & \\
\hline $\mathrm{R}^{2}$ (adjusted for $\mathrm{df}$ ) & 0.999142 & & & & \\
\hline
\end{tabular}

The statistics of the R-square $\left(\mathrm{R}^{2}\right)$ statistic is a measure of overall effect size. It indicates that the adjusted model explains $99.9938 \%$ and $99.9688 \%$ of the variability of sugar coloration and drying time, respectively. The adjusted R-square values are 99.9828\% and $99.9142 \%$ for both responses (sugar coloration and drying time, respectively). These values were used for comparing models having different numbers of explanatory variables.

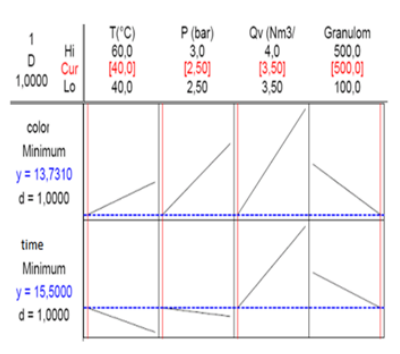

Figure 7: Optimal conditions.

Figure 7 reported that the optimal operational conditions. For drying sugar, were: at lower values of temperature, pressure and air flow and at higher level of particle size of sugar crystals. At the low level of particle size, "caking", lumping together of sugar crystals can occur during drying and could decrease the drying rate. Thus, it will affect the sugar quality.

\section{Conclusion}

In this study, we evaluated the effect of the operative conditions on fluid bed drying sugar by using as strategy the methodology of experimental design that aims to obtain maximum results for a smaller number of experiments. All data are used simultaneously to calculate every effect, which leads to a greater precision of the obtained results as well as the mathematical modeling of the experience.

A $2^{4-1}$ fractional factorial design was applied to establish a first-order model. After analysis of the effects this model permitted to show that the effect of sugar particle size on colour was the most important (in absolute value), whereas the effect of temperature and gas flow were lower and nearly equal. Pressure is a factor of lesser importance. Drying time is mostly influenced by the Temperature and gas flow. Analyzing the variance (ANOVA) showed that the model is highly significant and can adequately describe the experimental range.

\section{References}

1. Van der Poel PW, Schiweck H, Schwartz T (1998) Sugar Technology Beet and Cane Sugar Manufacture. ( $1^{\text {st }}$ edn), Verlag Dr Albert Bartens KG, Berlin, Germany. 
2. Rodgers T, Lewis C (1962) Int Sugar J 64: 359-362.

3. Potter OE, Keogh AJ (1995) Fuel Process Technol 4: 217-227.

4. Mourad M, Hamati M, Laguirie C (1995) Chem Eng J 60: 39-47.

5. Soponronnarit S, Yapha M, Prachayawarakorn S (1995) Cross-Flow Fluidized Bed Paddy Dryer: Prototype and Commercialization. Drying Technol 13(8-9): 2207-2216.

6. Niamnuy C, Devahastin S (2005) Drying kinetics and quality of coconut dried in a fluidized bed dryer. J Food Eng 66(2): 267-271.

7. Strumillo C, Grabowski S, Kaminski W, Zbicinski I (1989) Simulation of fluidized bed drying of biosynthesis products. Chem Eng Process 26: 139-145.

8. Tasirin SM, Kamarudin SK, Jaafar K, Lee KF (2007) The drying kinetics of bird's chillies in a fluidized bed dryer. J Food Eng 79(2): 695-705.

9. Tasirin SM, Kamarudin SK, Ghani JA, Lee KF (2007) Optimization of drying parameters of bird's eye chilli in a fluidized bed dryer. J Food Eng 80(2): 695-700.

10. Ng WK, Tan RBH (2008) Case study: Optimization of an industrial fluidized bed drying process for large Geldart Type D nylon particles. Powder Technol 180(3): 289-295.

11. Turker M, Kanarya A, Yuzgec U, Kapucu H, Senalp Z (2006) Drying of baker's yeast in batch fluidized bed. Chem Eng Process 45(12): 10191028.
12. Temple SJ, van Boxtel AJB (1999) Modeling of fluidized bad drying of black tea. Agric J Eng Res 74: 203-212.

13. Sahin 0, Bulutcu N (1999) Dehydration kinetics of sodium per borate tetra hydrates to monohydrate in a fluidized bed drier. Chem Eng Sci 54: 115-120.

14. Matsen JM (1996) Scale-up of fluidized bed processes: principals and practices. Powder Technol 88: 237-244.

15. Mujumdar AS, Devahastin S (2003) Applications for fluidized bed drying. Marcel Dekker, New York, USA.

16. Kaensup W, Wonguises S, Chutima S (1998) Drytng of pepper seeds using a combined microwave/fluidized bed dryer. Drying Technol 16(3-5): 853-862

17. Kaymark-Ertekin F (2002) Drying and Rehydrating Kinetics of Green and Red Peppers. J Food Sci 67(1): 168-175.

18. Reyes A, Alvarez PI, Marquardt FH (2002) Drying of carrots in a fluidized bed. i. effects of drying conditions and modelling. Drying Technol 20(7): 1463-1483.

19. Soponronnarit S, Yapha M, Prachayawarakorn S (1997) Drying characteristics of corn in fluidized bed dryer. Drying Technol 15(5): 1603-1615.

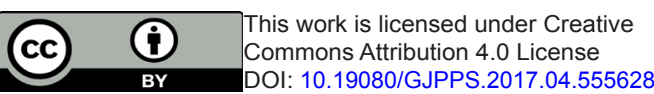

Your next submission with Juniper Publishers will reach you the below assets

- Quality Editorial service

- Swift Peer Review

- Reprints availability

- E-prints Service

- Manuscript Podcast for convenient understanding

- Global attainment for your research

- Manuscript accessibility in different formats

( Pdf, E-pub, Full Text, Audio)

- Unceasing customer service

Track the below URL for one-step submission https://juniperpublishers.com/online-submission.php 